\title{
ЭКОЛОГИЧЕСКАЯ БЕЗОПАСНОСТЬ
} И МИГРАЦИОННЫЕ ВЫЗОВЫ: СОЦИОЛОГИЧЕСКИЙ АНАЛИЗ СИТУАЦИИ В РОССИЙСКИХ РЕГИОНАХ *

\author{
С.А. Сарыглар ${ }^{1}$, С.Г. Максимова ${ }^{1}$, И.Н. Молодикова ${ }^{2}$ \\ ${ }^{1}$ Алтайский государственный университет, Барнаул, Россия \\ ${ }^{2}$ Центрально-Европейский университет, Будапешт, Венгрия
}

E-mail: Syldysma93@mail.ru,svet-maximova@yandex.ru,molodikova@hotmail.com

Проблема миграции напрямую связана с климатической и экологической ситуацией в регионах. Выбор того или иного места для иммиграции обусловлен не только социально-экономическими проблемами, но и экологической ситуацией в регионах выезда и въезда мигрантов. В статье представлен сравнительный анализ научных подходов к пониманию сущности и содержания понятия «экологическая безопасность», «миграция» и «миграционные процессы». Информационной базой являются материалы Федеральной службы государственной статистики по миграции населения, результаты исследования Всероссийского центра изучения общественного мнения (ВЦИОМ). Проведен анализ результатов мониторинга, отражающих динамику изменений оценок экологической ситуации в стране за последние годы. В 2017 г. общее количество прибывших в Россию составило 589033 чел. Большинство из них приехали из стран СНГ (Украина - 150182 чел., Казахстан - 71 680, Узбекистан — 64 073, Таджикистан - 63 467). В шести регионах России с различным этническим составом проведено социологическое исследование (2018) среди мигрантов $(\mathrm{n}=334)$. Проведен анализ миграционной ситуации в регионах и построена регрессионная модель факторов безопасности. На основе социологического исследования, проведенного Алтайским государственным университетом в 2018 г. (n = 600), проведен анализ экологической ситуации в российских регионах и построена факторная структура экологических рисков.

Ключевые слова: экологическая безопасность, миграчионные процессы, миграчия, миграчионная ситуаџия, экологическая ситуация, национальная безопасность, мигранты из стран СНГ.

\footnotetext{
* Публикация подготовлена в рамках выполнения гранта Президента Российской Федерации для государственной поддержки ведущих научных школ НШ-6535.2018.6 «Социальные риски и безопасность в условиях трансформации миграционных процессов в азиатском приграничье России» (2018-2019 гг.).
} 


\title{
ENVIRONMENTAL SECURITY AND MIGRATION CHALLENGES: A SOCIOLOGICAL ANALYSIS OF THE SITUATION IN RUSSIAN REGIONS
}

\author{
S.A. Saryglar ${ }^{1}$, S.G. Maximova ${ }^{1}$, I.N. Molodikova ${ }^{2}$ \\ ${ }^{\text {I}}$ Altai State University, Barnaul, Russia \\ ${ }^{2}$ Central European university, Budapest, Hungary \\ E-mail:Syldysma93@mail.ru,svet-maximova@yandex.ru,molodikova@hotmail.com
}

The problem of migration is directly related to the climate and environmental situation in the regions. The choice of this or that place for immigration is caused not only by social and economic problems, but also by the ecological situation in the regions of exit and enter of migrants. The article presents a comparative analysis of scientific approaches to the understanding of the essence and content of the concepts "environmental security", "migration" and «migration processes». The information base are the materials of the Federal State Statistics Service of Russia on population migration, results of researches by the Russian Public Opinion Research Center (VCIOM). The analysis of the results of monitoring reflecting the dynamics of changes in the assessments of the environmental situation in the country in recent years. In 2017, the number of migrants to Russia was over 589 033 people. Most of them came from CIS countries (Ukraine - 150182 people, Kazakhstan — 71 680, Uzbekistan — 64 073, Tajikistan — 63 467). In six regions of Russia with different ethnic structure we realized sociological research (2018) among migrants $(\mathrm{n}=334)$. The analysis of the migration situation in the regions is carried out and the regression model of the factors of security is constructed. On the basis of a sociological research conducted the Altai State University in 2018 ( $\mathrm{n}=$ 600 ), the analysis of the ecological situation in the Russian regions is carried out and the factor structure of ecological risks is constructed.

Keywords: environmental security, migration processes, migration, migration situation, environmental situation, national security, migrants from CIS countries.

\section{Введение}

Вопросы экологической безопасности с каждым годом становятся все более актуальными. Последствия изменений климата приобретают масштабный, разрушительный и необратимый характер. Согласно данным ООН, представленным в Докладе о Целях в области устойчивого развития, в 2016 г. глобальная температура достигла рекордного уровня, который примерно на $1,1{ }^{\circ} \mathrm{C}$ выше, чем в доиндустриальный период (Доклад..., 2017). Несмотря на успехи в области устойчивого развития, в том числе вступление в силу Парижского соглашения 4 ноября 2016 г., число людей, погибающих в результате стихийных бедствий, продолжает расти. Так, согласно Докладу, в период с 1990 по 2015 г. в результате стихийных бедствий погибло более 1,6 млн чел. 
Ухудшение экологической ситуации неразрывно связано с социально-экономическими, технологическими проблемами общества. И наоборот, ухудшение климата и экологии влечет за собой еще больше социально-экономических, демографических и технологических проблем. Поэтому важно подходить комплексно к решению данных проблем.

Понятие «экологическая безопасность» вошло в международную дискуссию в середине 1980-х гг. Одним из первых, кто использовал понятие «экологическая безопасность», был М.С. Горбачев, позже основавший Международный Зеленый Крест. Он говорил, что экологическая безопасность есть «органическая часть, ключевой момент международной безопасности» (Trombetta Maria Julia, 2008). Среди множества подходов и определений сложно выбрать единое базисное определение экологической безопасности. Одни авторы понимают ее как состояние защищенности от антропогенных факторов, стихийных бедствий и катастроф. Другие под экологической безопасностью понимают охрану окружающей среды. Третьи включают в нее и рациональное использование природных ресурсов. Согласно Е.Р. Дубровину и И.Р. Дубровину, экологическая безопасность - это прежде всего часть национальной безопасности государства, а также состояние, при котором «отсутствуют реальные и потенциальные угрозы экологическим интересам личности, общества и государства» (Дубровин Е.Р., Дубровин И.Р. 2009).

Концепция экологической безопасности рассматривает ее, главным образом, с точки зрения экологических угроз и катастроф и способности государства обеспечить безопасность. Некоторые авторы рассматривают экологическую безопасность через продовольственную, водную и энергетическую безопасность (Loring, Gerlach, \& Huntington, 2013). Авторы также подчеркивают взаимосвязь экологических и социально-экономических факторов. Изменение в одной области окружающей среды, например чрезмерное использование энергетических, водных ресурсов, может привести к изменениям в другой области - социально-экономической, политической среде общества.

Основываясь на данных подходах, экологическую безопасность можно определить как состояние защищенности жизненно-важных интересов личности, общества, государства от потенциальных и реальных угроз, вызванных антропогенными факторами, стихийными бедствиями и катастрофами (Тимофеев, Орлинская, 2017).

Глобальное ухудшение окружающей среды и нарастающая частота природных катастроф привели к появлению такого феномена, как «миграция, вызванная экологическими проблемами», или «экологическая миграция». Хотя главной и ключевой проблемой международной, региональной, внутрирегиональной миграции является социально-экономическое положение, но глобальные экологические изменения могут привести к колоссальному росту числа мигрантов. Так, в 2017 г., по данным Департамента по экономическим и социальным вопросам ООН, число мигрантов в мире составляло почти 258 миллионов человек (Международные мигранты..., 2017). Глобальные изменения окружающей среды могут привести к росту миграции, и к 2050 г. общая численность мигрантов в мире может составить почти 700 миллионов человек в год (Koko Warner, 2010). 
Миграция является одним из ключевых социальных явлений, определяющих судьбы миллионов людей в мире. Каждый человек в течение жизни не один раз сталкивается с миграционным вопросом. И будет верно сказать, что большинство людей проживают в местах, отличных от места их рождения. Миграция, внутренняя или международная, - это явление, которое имеет серьезные социально-психологические, экономические, политические последствия и вызывает изменения в каждой сфере общественной жизни.

В силу многоаспектности понятие «миграция» интерпретируется авторами по-разному. Некоторые авторы определяют миграцию как целенаправленное территориальное перемещение населения, обусловленное личностным волеизъявлением и объективными факторами, такими как социально-экономические, политические, демографические, межнациональные, межконфессиональные, экологические и другие. Данный подход предполагает три основных признака, определяющих миграцию: территориальное (географическое) перемещение (смена места жительства), временной показатель и цель передвижения (Полякова, 2016). Без учета критерия смены места жительства трудно отличить миграцию от других видов пространственных перемещений. Миграция возможна только при движении между условными границами. Она включает в себя все виды территориальной мобильности эпизодические, маятниковые или сезонные миграции, отличающиеся по времени и направленности (Кулешов, 2007).

Миграция как направленный процесс всегда начинается под воздействием определенных факторов. А. Коробов выделяет три условия, вследствие которых происходит миграция: «неудовлетворенность базовых потребностей населения на собственной территории, наличие источников удовлетворения данных потребностей за пределами этой территории и высокий уровень информированности населения о ситуации внутри границ своего жизненного пространства и за его пределами» (Коробов, 2003). С этой точки зрения миграция представляется как процесс территориального перемещения населения, вызванный стремлением удовлетворить жизненные базовые потребности (в пище, одежде, комфорте, а также в безопасности, здоровье и т.д.).

Статистический обзор миграционной и экологической ситуации в России

Миграция населения - сложный социально-экономический, географический, исторический, демографический процесс. Представляя собой один из ключевых факторов заселения земли, миграция оказывает огромное влияние на демографическую ситуацию в регионах. Более того, в случаях низкой рождаемости в регионах миграционные потоки обеспечивают рост численности населения.

Согласно данным Федеральной службы государственной статистики России, миграционный прирост в 2017 г. составил 211878 чел. В середине 2000-х гг. отмечалась относительная стабилизация миграционного прироста, которая в конце десятилетия сменилась ростом, а затем стабилизацией на более высоком уровне и очередным снижением (Омельченко, Максимова, Ноянзина, 2018). С 2010 г. наибольший уровень миграционного роста наблюдался с 2011 по 2014 г. Количество прибывших из стран СНГ преобладает над числом прибывших из других стран, что наблюдается 
на протяжении нескольких лет. Например, в 2017 г. общее количество прибывших в Россию составило 589033 чел. Четверть из них прибыли из Украины (150 182). Следующими по количеству прибывших являются такие страны, как Казахстан (71 680), Узбекистан (64 073), Таджикистан (63 467). Такая тенденция отражается и на количестве выбывших из России в страны СНГ (рис. 1).

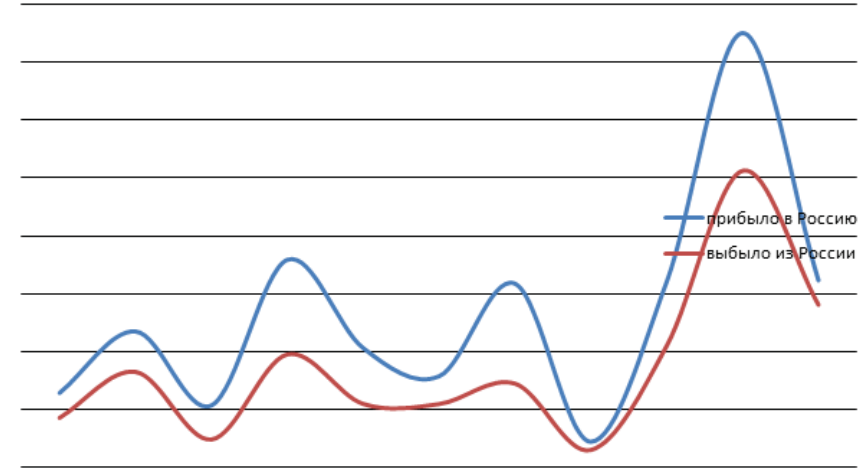

Рисунок 1 - Численность прибывших в Россию и убывших из России за 2017 г., чел.

Любые миграции, добровольные или принудительные, вызваны теми или иными причинами. Среди факторов развития миграции экологические проблемы играют немаловажную роль. Ухудшение экологической обстановки создает риск увеличения объемов миграции втрое и более.

В списке стран по индексу экологической эффективности за 2018 г. Россия занимает 52-е место среди 180 стран. Мониторинг экологической ситуации в России ежегодно проводится Всероссийским центром изучения общественного мнения (ВЦИОМ). Согласно результатам исследования 2018 г., наиболее острыми экологическими проблемами являются загрязнение воздуха заводами (16\%), мусорные свалки (11\%), несвоевременная уборка и вывоз мусора (10\%). Наблюдается рост положительных оценок экологической обстановки в стране. Если в 2009 г. только $39 \%$ опрошенных положительно оценили состояние окружающей среды, то в 2018 г. уже $59 \%$. В ближайшие несколько лет улучшения экологической обстановки ожидают $28 \%$ россиян, а $39 \%$ респондентов полагают, что ситуация не изменится (Экологическая ситуация..,, 2018).

Как показывает статистика, траектории международной миграции в России за последние годы остаются неизменными, количество мигрантов из стран СНГ преобладает над количеством мигрантов из стран дальнего зарубежья (Maximova, Noyanzina, Omelchenko, Maximova, 2018). В рейтинге стран по экологической эффективности эти страны (страны СНГ) находятся ниже, чем Россия (например, Украина на 109-м месте, Казахстан — 101-м, Таджикистан — 129-м и т.д.). 


\section{Методы исследования}

Целью данной статьи является определение взаимосвязи между миграционными процессами и экологической безопасностью в российских регионах.

Эмпирической базой статьи послужили, во-первых, данные социологического исследования среди мигрантов, проведенного в 2018 г. в российских регионах (Алтайский край, Амурская область, Астраханская область, Волгоградская область, Республика Тыва, Хабаровский край) в рамках выполнения гранта Президента Российской Федерации для государственной поддержки ведущих научных школ НШ-6535.2018.6 «Социальные риски и безопасность в условиях трансформации миграционных процессов в азиатском приграничье России», 2018-2019 гг. (n = 334). Во-вторых, это социологическое исследование среди населения по вопросам экологической безопасности, проведенное в Алтайском крае и Республике Алтай в 2018 г. $(\mathrm{n}=600)$.

В рамках первого исследования всего было опрошено 334 иностранных мигранта. Большинство опрошенных являются гражданами Узбекистана (48\%), Таджикистана (23\%), Казахстана (5\%), Украины (5\%), Киргизии (4\%) и других стран. Среди мигрантов, принявших участие в исследовании, $90 \%$ мужчины и лишь $10 \%$ женщины. Средний возраст мигрантов - 34 года.

В исследовании среди населения по вопросам экологической безопасности всего приняли участие 600 человек - жители Алтайского края и Республики Алтай. Среди опрошенных 44\% мужчин, 56\% женщин. Средний возраст респондентов - 43 года.

Методы сбора информации - анкетирование мигрантов и населения в возрасте от 18 до 75 лет.

Количественные данные обработаны с использованием программы для статистической обработки данных SPSS Statistics 20. Для подтверждения логики статистических выводов применены такие статистические методы, как частотный, факторный и регрессионный анализы.

\section{Результаты и обсуждение}

Анализ экологической ситуации и экологических рисков

Исследование по вопросам экологической безопасности показало, что экологическая обстановка в регионах не критична, но есть определенные угрозы (70\%). Экологическую ситуацию в регионах считают критической $17 \%$ опрошенных. Результаты исследования также показали, что ухудшение окружающей среды в регионах связано прежде всег, с такими проблемами, как ухудшение здоровья людей (14,5\%), антисанитарное состояние территории - мусор, свалки $(13,6 \%)$, загазованность воздуха $(12,9 \%)$, загрязнение водоемов $(12,8 \%)$, плохая загрязненная питьевая вода $(9,8 \%)$, исчезновение лесов, зеленых зон, парков $(8,5 \%)$, изменение климата $(7,5 \%)$ и др.

Для выявления экологических рисков, представляющих опасность для окружающей среды, был проведен факторный анализ методом главных компонент, включающий подпрограмму поворота факторных структур Varimax (критерий сферичности Бартлетта, значение статистики КМО $=0,825$, что больше 0,5$)$.

В результате анализа была получена 4-факторная структура, объясняющая $62 \%$ общей дисперсии переменных (табл. 1 ). 
Матрица повернутых компонент факторной модели экологических рисков

\begin{tabular}{l|c|c|c|c}
\multirow{2}{*}{} & \multicolumn{3}{|c}{ Компонента } \\
\cline { 2 - 5 } & $\mathbf{1}$ & $\mathbf{2}$ & $\mathbf{3}$ & $\mathbf{4}$ \\
\hline Аграрные предприятия (удобрения, мо- & 0,821 & & & \\
\hline Гильники животных и др.) & 0,805 & & & \\
\hline Брезвычайные происшествия & 0,780 & & & \\
\hline $\begin{array}{l}\text { Гранспортировка и захоронение радиоак- } \\
\text { тивных отходов }\end{array}$ & 0,721 & & & \\
Объекты энергетики (АЭС, ГЭС, ТЭЦ) & 0,505 & & & \\
\hline Вырубка лесов & & 0,778 & & \\
\hline Промышленные отходы & & 0,770 & & \\
\hline Промышленные предприятия & & 0,763 & & \\
\hline Бытовые отходы, мусор, свалки & & 0,679 & & \\
\hline Транспорт (авто, ж/д, авиа) & & 0,623 & & \\
\hline Чистота водоемов питьевой воды & & & 0,596 & \\
\hline Чистота воздуха & & & 0,793 & \\
\hline Чистота территорий & & & 0,555 & \\
\hline Охрана лесов, парков & & & & 0,844 \\
\hline Уровень шума & & & & 0,648 \\
\hline
\end{tabular}

Метод выделения: анализ методом главных компонент.

Метод вращения: Варимакс с нормализацией Кайзера.

а. Вращение сошлось за 6 итераций.

Первый фактор «Технико-экологические риски», информативность которого составила $19 \%$ общей дисперсии переменных $(\lambda=3,5)$ с максимальными нагрузками (факторные нагрузки более 0,5) вошли показатели, отражающие риски, связанные с развитием техносферы: аграрные предприятия $(0,82)$, чрезвычайные происшествия $(0,80)$, бытовая техника $(0,78)$, транспортировка и захоронение радиоактивных отходов $(0,72)$ и объекты энергетики (АЭС, ГЭС, ТЭЦ) $(0,50)$. По мнению большинства опрошенных, объекты промышленного производства и последствия их деятельности представляют большую опасность для окружающей среды (Maximova, Akulich, Pit, Noyanzina, Omelchenko, 2018).

Фактор «Риски устойчивых техногенных воздействий» (доля объясненной дисперсии - $16 \%, \lambda=2,9)$ включает показатели, связанные с рисками, возникаю- 
щими вследствие хозяйственной деятельности человека: вырубка лесов $(0,78)$, промышленные отходы $(0,77)$, промышленные предприятия $(0,76)$, бытовые отходы, мусор, свалки (0,68), транспорт (авто, ж/д, авиа) $(0,62)$. Проблемы такого рода не являются катастрофическими и стихийными, но носят постоянный и устойчивый характер. Так, ежедневно в России производится около 6,2 млрд т всех видов отходов. А поскольку в среднем перерабатывается только 10-15\% мусора, данные риски представляют также большую опасность для окружающей среды.

Третий фактор, «Риски загрязнения» (доля объясненной дисперсии - $13 \%$, $\lambda=2,4)$, включает показатели, отражающие вероятность загрязнения окружающей среды: чистота водоемов, питьевой воды $(0,59)$, чистота воздуха $(0,79)$, чистота территорий $(0,55)$. По мнению большинства респондентов, за последние 5 лет экологическая обстановка в регионах, а именно такие показатели, как чистота водоемов, воды, воздуха и чистота территорий, ухудшились.

Четвертый фактор, доля объясненной дисперсии которого составила $12 \%$ $(\lambda=2,2)$, включил такие показатели, как охрана лесов, зеленых зон, парков $(0,84)$ и уровень шума $(0,64)$. Ухудшение деятельности в сфере охраны лесов, парков также представляет опасность для окружающей среды.

Таким образом, в первый фактор с наибольшими нагрузками вошли показатели, связанные с технико-экологическими рисками. Масштабность промышленной деятельности и глобальные климатические изменения делают экосистему крайне уязвимой к возникновению аварийных ситуаций, способных нанести необратимый ущерб окружающей среде. Это подчеркивает необходимость обеспечения эффективной и результативной работы с техногенными объектами и проведение мероприятий по оценке, контролю экологических рисков.

Анализ миграционной ситуации в российских регионах

Ухудшение экологической обстановки создает риск увеличения объемов миграции населения. Миграция является одним из ключевых социальных явлений, определяющих судьбы миллионов людей в мире. Каждый человек в течение жизни не один раз сталкивается с миграционным вопросом.

В рамках социологических исследований, проведенных в российских регионах по вопросам миграции, было опрошено 334 иностранных мигранта. Большинство мигрантов являются гражданами стран СНГ (Узбекистан - 48\%, Таджикистан - 23\%, Казахстан - 5\%, Украина - 5\%, Киргизия - 4\% и др.). Основная цель пребывания мигрантов в России - это трудовая деятельность (87\%).

В связи с тем, что большинство мигрантов являются трудовыми, выбор того ли иного региона для миграции обусловлен прежде всего наличием рабочего места. Так, треть опрошенных на вопрос, почему они приехали именно в данный регион, ответили, что приехали в российские регионы, потому что их ждали на работу (37\%). Немаловажную роль при выборе страны, региона для миграции играют родственные и дружеские связи. Некоторая часть мигрантов ответили, что приехали в данный регион, потому что у них были знакомые, друзья $(18,9 \%)$ и родственники $(18,2 \%)$. Климат и природа региона, комфортные условия проживания играют важную роль при выборе региона для 5\% опрошенных. Хотя работа и наличие 
дружеских, родственных связей играют ключевую роль при выборе регионов для большинства мигрантов, климат и экологическая обстановка региона также имеют большое значение.

Экологическая безопасность является одним из важных структурных элементов национальной безопасности. В рамках исследования респондентам был задан вопрос «Насколько в целом Вы ощущаете себя в безопасности?». Большинство мигрантов ответили, что полностью ощущают себя безопасности (50\%). Лишь $2 \%$ опрошенных ответили, что не ощущают себя в безопасности.

Таблица 2

Регрессионная модель факторов безопасности мигрантов в стране прибытия

\begin{tabular}{|c|c|c|c|c|c|c|}
\hline & \multirow[t]{2}{*}{ Модель } & \multicolumn{2}{|c|}{$\begin{array}{c}\text { Нестандартизо- } \\
\text { ванные коэф- } \\
\text { фициенты }\end{array}$} & \multirow{2}{*}{$\begin{array}{c}\text { Стан- } \\
\text { дарти- } \\
\text { зован- } \\
\text { ные } \\
\text { коэф- } \\
\text { фици- } \\
\text { енты }\end{array}$} & \multirow[t]{2}{*}{$\mathbf{t}$} & \multirow[t]{2}{*}{ Знч. } \\
\hline & & B & $\begin{array}{c}\text { Стд. } \\
\text { Ошибка }\end{array}$ & & & \\
\hline \multirow{5}{*}{1} & (Константа) & 1,067 &, 064 & & 16,747 & 000 \\
\hline & $\begin{array}{l}\text { Как в целом относится к Вам ра- } \\
\text { ботодатель, управляющий персо- } \\
\text { нал, с которыми Вам приходится } \\
\text { встречаться во время работы? }\end{array}$ &,- 002 & ,003 &,- 032 &,- 496 & ,620 \\
\hline & $\begin{array}{l}\text { Как, Вы считаете, население } \\
\text { в данном регионе относится } \\
\text { к мигрантам? }\end{array}$ & ,003 & ,001 & , 197 & 2,906 & ,004 \\
\hline & $\begin{array}{l}\text { Возможно ли, на Ваш взгляд, вза- } \\
\text { имопонимание и сотрудничество } \\
\text { между коренными жителями стра- } \\
\text { ны и приезжими, мигрантами? }\end{array}$ &, 003 & ,001 & , 128 & 1,888 & ,060 \\
\hline & $\begin{array}{l}\text { Какова, Вы считаете, полити- } \\
\text { ка по отношению к мигрантам } \\
\text { в России? }\end{array}$ & ,039 & ,027 & ,092 & 1,440 &, 151 \\
\hline
\end{tabular}

Зависимая переменная: Насколько Вы ощущаете себя в безопасности?

Для выявления значимых факторов, влияющих на чувство безопасности, был осуществлен регрессионный анализ. В качестве зависимой переменной был определен показатель - чувство безопасности, включающий позитивный полюс (полностью или скорее ощущаю себя в безопасности) и отрицательный полюс (не очень или совсем не ощущаю себя в безопасности). В качестве независимых переменных, установлены следующие факторы: отношение населения к мигрантам, взаимопонимание и сотрудничество между коренными жителями и приезжими, отношение 
работодателя и управляющего персонала к мигрантам и политика по отношению к мигрантам в России (табл. 2).

Коэффициент детерминации (R-квадрат) для данной модели равен 0,082, соответственно 8,2\% дисперсии зависимой переменной объясняется влиянием независимой переменной.

Как представлено в модели, отношение населения к мигрантам влияет на чувство безопасности больше, чем политика по отношению мигрантам или отношение работодателя и сотрудников. Кроме того, связь между показателем взаимопонимания, сотрудничества между коренными жителями и приезжими и показателем безопасности существенна. Те респонденты, кто считает, что взаимопонимание и сотрудничество между коренными жителями страны и приезжими возможно, ответили, что полностью ощущают себя в безопасности.

Таковы базовые условия, влияющие на уровень безопасности. Безопасность граждан, в частности иностранных мигрантов в странах прибытия, возрастает при наличии уважительного, благожелательного отношения к мигрантам со стороны местных жителей и взаимопонимания, сотрудничества между ними.

\section{Заключение}

Действительно, последствия изменений климата приобретают масштабный, разрушительный характер. Как показали результаты социологического исследования, экологическая ситуация в российских регионах не критическая, но есть определенные угрозы. Особую опасность представляют риски эколого-техногенного характера. Согласно результатам исследования среди мигрантов, климат и природа региона играют немаловажную роль при выборе региона для иммиграции. Результаты государственной статистики и социологических исследований показывают, что количество прибывших в Россию из стран СНГ преобладает над числом прибывших из других стран, что наблюдается на протяжении нескольких лет. Также стоит отметить, что по показателям экологической эффективности данные страны (страны СНГ) занимают строки ниже, чем Россия.

С каждым годом количество экологических катастроф продолжает расти. Ухудшение климата и экологии влечет за собой еще больше социально-экономических, демографических и технологических проблем. Изменение климата приводит к массовому перемещению населения, миллионы людей вынуждены покидать свои родные страны. Поэтому важно подходить комплексно к решению данных проблем, обеспечить эффективную и результативную работу по оценке, контролю экологических рисков и обеспечению национальной безопасности.

\section{БИБЛИОГРАФИЧЕСКИЙ СПИСОК}

Гридина Ю.А., Власова Т.А. Экологическая безопасность России. В кн.: Экология и управление природопользованием: сборник научных трудов Первой Всероссийской научно-практической конференции с международным участием. Вып. 1 / Под ред. А.М. Адама. Томск: Литературное бюро, 2017. С. 90-91. 
Доклад о Целях в области устойчивого развития. Организация Объединенных Наций (OOH), 2017. URL: https://unstats.un.org/sdgs/files/report/2017/TheSustainableDev elopmentGoalsReport2017_Russian.pdf (дата обращения 18.11.2017).

Дубровин Е.Р., Дубровин И.Р. Экологическая безопасность в системе национальной безопасности России. Мир человека, 2009, No.1, 73-79.

Коробов А.А. Структурно-генетический подход к анализу миграции населения (теоретический аспект). Вестник Саратовского государственного социально-экономического университета, 2003, №. 6, 97-101.

Кулешов Д.Н. Теоретико-методологические аспекты изучения миграции населения. Вестник ВЭГУ, 2007, №. 31-32, 196.

Международные мигранты: пересмотр 2017. OOH, 2017. URL: http://www.un.org/en/ development/desa/population/migration/data/estimates2/estimates17.shtml (дата обращения 19.11.2018).

Полякова Н.В. К вопросу о понятиях «миграция» и «нелегальная миграция»: доктрина и законодательство. Вестник Барнаульского юридического института МВД России, 2016, 1(30), 87-90.

Тимофеев Г.А., Орлинская О.М. Экологическая безопасность в системе национальной безопасности Российской Федерации. Власть, 2017, №. 2(25), 69-74.

Koko Warner. Global environmental change and migration: Governance challenges. Global Environmental Change, 2010, No. 3, 402-413. URL: https://www.sciencedirect. com/science/article/abs/pii/S0959378009001058.

Loring P.A., Gerlach S.C., \& Huntington H.P. The new environmental security: Linking food, water, and energy for integrative and diagnostic social-ecological research. Journal of Agriculture, Food Systems, and Community Development. Advance online publication, 2013. URL: http://dx.doi.org/10.5304/jafscd.2013.034.005.

Maximova S.G., Akulich M.M., Pit V.V., Noyanzina O.E., Omelchenko D.A. Social moods as ecological risk perception in residential area around nuclear power plants (regional analysis). Ukrainian Journal of Ecology, 8(1), 409-419. 2018.

Maximova S.G., Noyanzina O.E., Omelchenko D.A. and Maximova M.M. The Russianspeakers in the CIS countries: migration activity and preservation of the Russian language. MATEC Web of Conferences 212, 10005 (2018). ICRE 2018. URL: http://doi.org/10.1051/ matecconf/201821210005.

Trombetta Maria Julia. Environmental security and climate change: analysing the discourse, Cambridge Review of International Affairs, 2008, 21(4), 585-602, DOI: 10.1080/09557570802452920.

\section{REFERENCES}

Gridina YU.A., Vlasova T.A. (2017). Ehkologicheskaya bezopasnost' Rossii [Ecological security of Russia]. In: Ehkologiya i upravlenie prirodopol'zovaniem: sbornik nauchnykh trudov Pervoj Vserossijskoj nauchno-prakticheskoj konferentsii s mezhdunarodnym uchastiem [Ecology and management: scientific works collection of the I All-Russian scientific-practical conference with international participation]. Vol. 1. / Ed. by A.M. Adama. 
Tomsk: Literaturnoe byuro, S. 90-91.

The sustainable development goals report (2017). UN. Available at: https://unstats.un.org/ sdgs/files/report/2017/TheSustainableDevelopmentGoalsReport2017_Russian.pdf (Accessed 18.11.2017).

Dubrovin, E.R., Dubrovin, I.R. (2009). Ehkologicheskaya bezopasnost' v sisteme natsional'noj bezopasnosti Rossii [Ecological security in the system of national security of Russia]. Mir cheloveka [Human's world], No. 1, 73-79.

Korobov, A.A. (2003). Strukturno-geneticheskij podkhod k analizu migratsii naseleniya (teoreticheskij aspekt) [Structural-genetic approach to the analysis of migration]. Vestnik Saratovskogo gosudarstvennogo sotsial'no-ehkonomicheskogo universiteta [Herald of the Saratov State Socio-Economic University], No. 6, 97-101.

Kuleshov, D.N. (2007). Teoretiko-metodologicheskie aspekty izucheniya migratsii naseleniya [Theoretico-methodological aspects of migration research]. Vestnik VEGU, No. 31-32, 196.

International migrant stock: The 2017 revision. UN open data, 2017. Available at: http:// www.un.org/en/development/desa/population/migration/data/estimates2/estimates 17. shtml (Accessed 19.11.2018).

Polyakova, N.V. (2016). K voprosu o ponyatiyakh «migratsiya» $\mathrm{i}$ «nelegal'naya migratsiya»: doktrina i zakonodatel'stvo [On the issue of definition of the notion «illegal migration»: doctrine and law]. Herald of the Barnaul Law Institute of the Ministry of Internal Affairs of Russia, 1(30), 87-90.

Timofeev, G.A., Orlinskaya, O.M. (2017). Ehkologicheskaya bezopasnost' v sisteme natsional'noj bezopasnosti Rossijskoj Federatsii [Ecological security in the system of national security of the Russian Federation]. Vlast, 2(25), 69-74.

Koko, Warner. (2010). Global environmental change and migration: Governance challenges. Global Environmental Change, No. 3, 402-413. Available at: https://www.sciencedirect.com/science/article/abs/pii/S0959378009001058.

Loring, P.A., Gerlach, S.C., \& Huntington, H.P. (2013). The new environmental security: Linking food, water, and energy for integrative and diagnostic social-ecological research. Journal of Agriculture, Food Systems, and Community Development. Advance online publication. Available at: http://dx.doi.org/10.5304/jafscd.2013.034.005.

Maximova, S.G., Akulich, M.M., Pit, V.V., Noyanzina, O.E., Omelchenko, D.A. (2018). Social moods as ecological risk perception in residential area around nuclear power plants (regional analysis). Ukrainian Journal of Ecology, 8(1), 409-419.

Maximova, S.G., Noyanzina, O.E., Omelchenko, D.A. and Maximova, M.M. (2018). The Russian-speakers in the CIS countries: migration activity and preservation of the Russian language. MATEC Web of Conferences 212, 10005. ICRE 2018. Available at: http://doi. org/10.1051/matecconf/201821210005.

Trombetta, Maria Julia. (2008). Environmental security and climate change: analysing the discourse. Cambridge Review of International Affairs, 21(4), 585-602, DOI: $10.1080 / 09557570802452920$. 